\title{
OXYGEN ENHANCED COMBUSTION FOR NOx CONTROL
}

\author{
QUARTERLY TECHNICAL PROGRESS REPORT
}

Reporting Period Start Date: July 2000

Reporting Period End Date: September 2000

Principal Authors:

Principal Investigator, Combustion Development: $\quad$ Lawrence E. Bool

Principal Investigator, OTM Development:

Jack C. Chen

Program Manager and Business Officer:

David R. Thompson

Date Report was Issued: October 2000

DOE AWARD NO. DE-FC26-00NT40756

Submitted by:

Praxair, Inc.

175 East Park Drive

Tonawanda, NY 14151 


\section{DISCLAIMER:}

This report was prepared as an account of work sponsored by an agency of the United States Government. Neither the United States Government nor any agency thereof, nor any of their employees, makes any warranty, express or implied, or assumes any legal liability or responsibility for the accuracy, completeness, or usefulness of any information, apparatus, product, or process disclosed, or represents that its use would not infringe privately owned rights. Reference herein to any specific commercial product, process, or service by trade name, trademark, manufacturer, or otherwise does not necessarily constitute or imply its endorsement, recommendation, or favoring by the United States Government or any agency thereof. The views and opinions of authors expressed herein do not necessarily state or reflect those of the United States Government or any agency thereof.

\section{ABSTRACT:}

This quarterly technical progress report will summarize work accomplished for the Program through the second quarter July - September 2000 in the following task areas: Task 1Oxygen Enhanced Combustion, Task 2-Oxygen Transport Membranes and Task 4-Program Management.

The program is proceeding in accordance with the objectives for the first year. OTM tube characterization is well underway, the design and assembly of the high pressure permeation test facility is complete and the facility will be in full operation during the next quarter.

Combustion testing has been initiated at both the University of Arizona and Praxair. Testing at the University of Arizona has experienced some delays; steps have been take to get the test work back on schedule. Completion of the the first phase of the testing is expected in next quarter.

Combustion modeling has been started at both REI and Praxair, preliminary results are expected in the next quarter. 


\section{TABLE OF CONTENTS}

A. Executive Summary $\quad$ Page 3

B. Experimental Methods $\quad$ Page 4

B.1. Task 1 Oxygen Enhanced Combustion Page 4

B.1.1. Task 1.1.1 Combustion Modeling Page 4

B.1.2. Task 1.1.2 Lab-scale Parametric Testing Page 4

B.1.3. Task $1.2 \mathrm{O}_{2}$ Injector Design, Testing Page 4

B.2. Task 2.1 OTM Materials Development Page 4

B.3. Task 2.2 OTM Element Development Page 5

B.4. Task 2.3 OTM Process Development Page 5

C. Results and Discussion Page 5

C.1. Task 1 Oxygen Enhanced Combustion Page 5

C.1.1. Task 1.1.1 Combustion Modeling Page 5

C.1.2. Task 1.1.2 Lab-scale Parametric Testing Page 5

C.1.3. Task $1.2 \mathrm{O}_{2}$ Injector Design, Testing Page 6

C.2. Task 2.1 OTM Materials Development Page 6

C.3. Task 2.2 OTM Element Development Page 6

C.4. Task 2.3 OTM Process Development Page 6

C.5. Task 4 Program Management $\quad$ Page 7

$\begin{array}{ll}\text { D. Conclusion } & \text { Page } 7\end{array}$

E. References $\quad$ Page 8

F. Appendix - Limited Rights Data $\quad$ Page A1 


\section{A. Executive Summary}

Initial oxygen enhanced combustion modeling (Task 1.1.1) efforts have focused on modeling $\mathrm{O}_{2}$ enhanced combustion in the Keystone boiler - a corner fired boiler fitted with an ABB Low-NOx Concentric Firing System (LNCFS) level III. Efforts have also focused on further enhancement of the comprehensive modeling capabilities of the existing coal combustion model. Full inspection of each of the model components was conducted, and the enhanced model was tested against several defined cases.

Laboratory-scale parametric testing (Task 1.1.2) commenced this quarter. Coal burning testing under excess air conditions was conducted, and steady operation was achieved for several days. Experimental difficulties were encountered with the main air compressor and coal feeder which were resolved. A flaw in the safety shut-off sequence was discovered which resulted in an air heater damaged beyond repair. A revamped emergency shut-off system is currently being installed. Coal burning operations should continue by the end of October. Staged combustion testing with $\mathrm{O}_{2}$ is expected to commence mid-November.

$\mathrm{O}_{2}$-based injector design and testing (Task 1.2) is on schedule. The apparatus for the $\mathrm{O}_{2}$-based injector tester have been completed and are in place and shakedown experiments have been performed. The hot oxygen burner was run successfully utilizing a solid fuel. Further testing will be conducted next quarter.

The objective of the OTM materials development program (Task 2.1) is to ascertain a suitable material composition that can be fabricated into elements capable of producing the target oxygen flux under the operating conditions. The candidate OTM material, designated PSO1, was selected due to high oxygen flux values measured on discs at $1000^{\circ} \mathrm{C}$ using a helium purge gas and air feed gas. In the first quarter of this program the thermo-mechanical stability of PSO1 was determined. Initial results indicate the need to improve the mechanical properties to ensure adequate reliability under commercial operation. Work in the second quarter of this program has concentrated on the development of new materials to improve their properties. Particular emphasis was placed on the benefits of introducing a second phase to improve mechanical properties.

Continued progress was made in OTM element development (Task 2.2). A series of tests was performed to assist in determining powder specifications for manufacturing PSO1 elements. Included in these tests was the "supergrind" material discussed in the first technical progress report ${ }^{1}$. In September element deliveries commenced with the manufacture of six (6) PSO1 elements. Densities of these elements, measured via Archimedes method, were $97 \%$ of theoretical density.

OTM process development (Task 2.3) is on schedule. Construction of the permeation test facility has been completed. The system currently is undergoing internal safety review. The apparatus should be approved for safe operation in October 2000, with reactor shakedown experiments and OTM testing to begin shortly thereafter.

Program management (Task 4) continued on track during the second quarter of this program. Two sub-contracts have been executed. Project documentation has been prepared and delivered to the US DOE in accordance with the cooperative agreement. 


\section{B. Experimental Methods}

\section{B.1. Oxygen Enhanced Combustion (Task 1) Experimental Methods}

\section{B.1.1. Combustion Modeling (Task 1.1.1) Experimental Methods}

During this reporting period, initial combustion modeling efforts have focused on modeling $\mathrm{O}_{2}$ enhanced combustion in the Keystone boiler - a corner fired boiler fitted with an ABB Low-NOx Concentric Firing System (LNCFS) level III.

Additional combustion modeling efforts have focused on two major items: (a) to enhance further the comprehensive modeling capabilities of an existing coal combustion model, and (b) to conduct full inspection of each of the model components and to test the enhanced model against several defined cases.

\section{B.1.2. Laboratory-scale Parametric Testing (Task 1.1.2) Experimental Methods}

Problems involving the air compressor coal feeder were resolved and testing with coal initiated. An Illinois \# 6 pulverized coal was burned under excess air conditions, and steady operation was achieved for several days.

\section{B.1.3. Oxygen-based Injector Design and Testing (Task 1.2) Experimental Methods}

The apparatus for the oxygen injection tester have been completed and shakedown testing has been conducted. The hot oxygen burner was run successfully utilizing a solid fuel.

\section{B.2. OTM Materials Development (Task 2.1) Experimental Methods}

\section{B.2.1. Development of Modified Material Compositions}

Characterization of PSO1 has shown that further improvement of mechanical and electrochemical properties is required for commercial use. First quarter results revealed that the creep of PSO1 is too large for long-term operation. Flux measurements at atmospheric pressure using an inert purge gas indicate that the flux target will require improved architecture. Efforts are underway to improve strength via improved processing and improved compositions. Characterization procedures have included flux measurements, electrical conductivity, surface exchange, bulk diffusion, and mechanical strength measurements.

\section{B.2.2. Characterization of PSO1 and Modified Material Compositions}

A uniaxial compressive creep testing apparatus was constructed at UMR under a separate program. This instrument is based on a modified vertical dilatometer. Creep measurements can be carried out at different temperatures and different loads. Creep measurements have been performed at 900 and $1200^{\circ} \mathrm{C}$ on sections of a PSO1 element.

The mechanical strength of the modified composition was measured using 4-point bend measurements at room temperature.

A permeation cell for measuring the oxygen flux of 1-inch diameter discs of OTM materials is in place. Oxygen fluxes can be measured on discs with a thickness of 300 microns to $2 \mathrm{~mm}$, at 
atmospheric pressure. Flux tests were conducted on discs and elements of modified compositions using a helium purge gas and air feed stream at temperatures ranging from 700 to $1050^{\circ} \mathrm{C}$.

\section{B.3. OTM Element Development (Task 2.2) Experimental Methods}

XRD powder data was re-analyzed at UMR. It was determined that PSO1 exhibits a theoretical density of approximately $6.8 \%$ less than the theoretical density value used for last quarter.

Disks were pressed and sintered to compare standard PSO1 powder to a "supergrind" PSO1 powder. The results seem to show no significant difference in the density between the standard and "supergrind" material.

Optimization of element sintering temperature continued. Six (6) PSO1 elements were manufactured to the test facility specifications. The densities of the elements were determined via Archimedes method to be $97 \%$ of theoretical density.

\section{B.4. OTM Process Development (Task 2.3) Experimental Methods}

Several items were added to the high-pressure permeation test facility to ensure safe reactor operation. Check valves were added to prevent backflow of process gases into gas manifolds. A relief valve has been added to protect the mass flow controllers in the event of a pressure regulator failure. The system is currently undergoing internal safety reviews.

\section{Results and Discussion}

\section{C.1. Oxygen Enhanced Combustion (Task 1) Results and Discussion}

\section{C.1.1. Combustion Modeling (Task 1.1.1) Results and Discussion}

Combustion modeling efforts have focused on modeling $\mathrm{O}_{2}$ enhanced combustion in the Keystone boiler - a corner fired boiler fitted with an ABB Low-NOx Concentric Firing System (LNCFS) level III. The LNCFS Level III system utilizes both Close Coupled Over-Fire Air (CCOFA) and Separated Over-Fire Air (SOFA). Initial results have suggested that a more effective design is desired to deliver the oxygen-enriched air.

Additional combustion modeling efforts have focused on the further enhancement of the comprehensive modeling capabilities of the existing coal combustion model. Full inspection of each of the model components was conducted and the enhanced model was tested against several defined cases. These above task-items were considered important before any commencement of full-scale model application, and hence were essentially completed.

\section{C.1.2. Laboratory-scale Parametric Testing (Task 1.1.2) Results and Discussion}

Experimental difficulties were experienced with the coal combustor. Problems involving the air compressor coal feeder were resolved and testing with coal initiated. An Illinois \# 6 pulverized coal was burned under excess air conditions, and steady operation was achieved for several days.

A subsequent flaw in the safety shut-off sequence was discovered when the power to the compressor failed, but the gas flame in the furnace failed to extinguish, thus failing to trip the gas flow. Also the air heater failed to shut off, and was consequently damaged beyond repair. This episode reinforced the 
need to tie emergency shut-offs into both the gas line (Maxon valve with manual reset) and into the $\mathrm{O} 2$ line, both to be tripped in the case of a) flame out; b) power failure; c) air compressor failure; d) high exit temperature; e) exit blower failure. This safety system is currently being installed.

\section{C.1.3. Oxygen-based Injector Design and Testing (Task 1.2) Results and Discussion}

Th oxygen injector test apparatus assembly has been completed and shakedown testing was conducted. The hot oxygen burner was run successfully on a solid fuel. Further testing will be done next quarter.

\section{C.2. OTM Materials Development (Task 2.1) Results and Discussion}

Efforts this quarter focussed on improved material strength via improved processing and manufacture of improved compositions.

The high temperature mechanical properties of PSO1 were studied. Results indicate that improvements in the thermomechanical of PSO1 are required given the current preferred architecture of the OTM element. Work is focusing on improving the thermomechanical properties of the material and modifying the OTM architecture.

The effect of modifying the composition was tested using 4-point bend measurements at room temperature. Preliminary results indicate that the modification increases strength and the Weibull modulus at certain compositions compared to the original PSO1 reported last quarter. One PSO1 modified composition appears to show a decrease in strength, however, this effect is being further investigated to confirm that it is a real phenomenon and not an artifact of improper sample preparation.

Flux tests were conducted on modified compositions PSO1 Composition modifications were successful in achieving a more desirable phase behavior over a wide range of temperatures. However, there appears to be a reduction in flux. In order to meet the flux targets thinner membranes, improved architecture and composition improvements will be investigated.

\section{C.3. OTM Element Development (Task 2.2) Results and Discussion}

PSO1 powder was re-analyzed at UMR and determined to have a theoretical density of approximately $6.8 \%$ less than the theoretical density value used for last quarter. Disks from the standard PSO1 powder and the "supergrind" PSO1 powder were identically prepared and measured for density. No significant difference in density between the standard and "supergrind" PSO1 was observed.

OTM element sintering tests were conducted at different temperatures with density results indicating no significant difference. Six (6) elements were manufactured according to the high-pressure permeation tester specifications and delivered in September.

\section{C.4. OTM Process Development (Task 2.3) Results and Discussion}

Construction of the high-pressure permeation tester has been completed. Several items were added to the test facility to ensure safe reactor operation including check valves and relief valves. The system currently is undergoing internal safety review. The apparatus should be approved for safe operation in October 2000.

OTM element and seal dimensions and configurations continue to be assessed to ensure optimal seal performance. 


\section{C.5. Program Management (Task 4) Results and Discussion}

The Program Management highlights for the second of the quarter US DOE $\mathrm{NO}_{\mathrm{x}}$ program are as follows:

- Sub-Contracts have been executed with Alstom Power and Reaction Engineering International (REI).

- Labor hours and costs continued to be monitored via accounts established within the Praxair accounting system.

- A project review meeting was held on September 25, 2000 with all members of the team present.

\section{Conclusion}

Combustion modeling (Task 1.1.1) efforts have commenced this quarter. Modeling oxygen-enhanced combustion in the Keystone boiler was conducted. Initial results have suggested that a more effective design to deliver the oxygen-enriched air is desired. Optimization of this model will continue next quarter. Also, the comprehensive modeling capabilities of an existing coal combustion model were determined, then further enhancement of the model was performed. Full inspection of each of the model components was conducted, and the enhanced model was tested against several defined cases. In future work, the model will be used to assess design parameters.

Laboratory-scale parametric testing (Task 1.1.2) is underway. Experimental difficulties were encountered with the test apparatus and were resolved. Coal burning testing under excess air conditions was conducted, and steady operation was achieved for several days. A flaw in the safety shut-off sequence was discovered which resulted in a cessation of operations until installation of an improved emergency shut-off system is complete. Coal burning operations should resume by the end of October. Staged combustion testing with $\mathrm{O}_{2}$ is expected to commence mid-November.

Oxygen-based injector design and testing (Task 1.2) is on schedule. The apparatus for the $\mathrm{O}_{2}$-based injector tester are in place and shakedown experiments have been performed. The hot oxygen burner was run successfully utilizing a solid fuel. Further testing will be conducted next quarter.

OTM materials development (Task 2.1) optimization and characterization continued. Development of new materials with high flux over a wide temperature range will continue. Thermal expansion coefficient (TEC) measurement of compositions will be conducted to enable system integration.

Efforts are also underway to improve the mechanical properties and robustness via improved processing and optimization of composition and microstructure. Further work will be performed examining the thermo-chemical and thermo-mechanical properties of PSO1 type materials. A new test facility will be commissioned that will increase the number of specimens to be examined for key mechanical properties.

OTM element development (Task 2.2) fulfilled the first set of deliverables: six (6) PSO1 elements were manufactured to the test facility specifications and delivered in September. Future work for the next quarter will consist of manufacturing PSO1 elements in two nominal dimensions for the test reactor. The work will vary processing parameters to increase OTM mechanical properties. Tests for the first month of the third quarter will also include a thermal shock viability test. Powder QC specifications for this stage of the program are expected to be finalized in December. 
OTM process development work in Task 2.3 is on schedule. Construction of the high-pressure permeation tester has been completed and is currently undergoing internal safety review. Proposed future work includes testing the functionality of the reactor and OTM element performance through initial tests at $900^{\circ} \mathrm{C}$ and atmospheric pressure with a helium or nitrogen purge. Seal performance will also be assessed.

\section{E. References}

1. Thompson et. al, "Oxygen Enhanced Combustion for NOx Control”, Quarterly Technical Progress Report for US DOE Award No. DE-FC26-00NT40756, July 2000 